\title{
Predictable Imaging Signs of Cauda Equina Entrapment in Thoracolumbar and Lumbar Burst Fractures with Greenstick Lamina Fractures
}

\author{
Toyomi Yoshiiwa, Masashi Miyazaki, Ryuzo Kodera, Masanori Kawano, Hiroshi Tsumura \\ Department of Orthopaedic Surgery, Faculty of Medicine, Oita University, Yufu, Japan
}

\begin{abstract}
Study Design: A retrospective study.
Purpose: The aim of present study was to investigate imaging findings suggestive of cauda equina entrapment in thoracolumbar and lumbar burst fractures.

Overview of Literature: Burst fractures with cauda equina entrapment can cause neurologic deterioration during surgery. However, dural tears and cauda equina entrapment are very difficult to diagnose clinically or radiographically before surgery.

Methods: Twenty-three patients who underwent spinal surgery for thoracolumbar or lumbar burst fractures were enrolled in this study. In magnetic resonance imaging T2-weighted images of the transverse plane, we defined cauda equina notch sign (CENS) as a v-shaped image that entrapped cauda equina gathers between lamina fractures. We evaluated the fractured spine by using CENS and lamina fractures and the rate of available space for the spinal canal at the narrowest portion of the burst fracture level. We classified patients into entrapment group or non-entrapment group, based on whether cauda equina entrapment existed.

Results: Lamina fractures were detected in $18(78.3 \%)$ and CENS were detected in $6(26.1 \%)$ of 23 burst-fracture patients. Cauda equina entrapment existed in all the patients with CENS. In addition, the rate of available space for the spinal canal increased according to logistic regression. The size of the retropulsed fragment in the spinal canal was the most reliable of all the factors, suggesting cauda equina entrapment.

Conclusions: CENS was the most predictable sign of cauda equina entrapment associated with burst fractures.
\end{abstract}

Keywords: Burst fracture; Dural tear; Cauda equina entrapment; Lamina fracture; Magnetic resonance imaging

\section{Introduction}

Burst fracture of the spine is defined as a failure of the anterior and middle columns of the vertebral segment [1]. A retrospective study by Keenen et al. [2] involving patients with spinal fractures showed a $7.7 \%$ incidence of dural tears in surgically-treated patients. Lumbar spine fracture-associated cauda equine entrapment was first re- ported by Miller et al. [3]. They documented the presence of dural lacerations and herniation of the cauda equina in patients with thoracolumbar spine fractures, associated with separation of the pedicles; and pointed out extrusion of the cauda equina rootlets outside the dural sac and posterior entrapment of these neurologic elements in the lamina fractures.

Furthermore, cauda equina entrapment may cause

Received Feb 17, 2013; Revised May 2, 2013; Accepted Jun 29, 2013

Corresponding author: Masashi Miyazaki

Department of Orthopaedic Surgery, Oita University, Faculty of Medicine,

1-1 Idaigaoka, Hsama-machi, Yufu 879-5593, Japan

Tel: +81-97-586-5872, Fax: +81-97-586-6647, E-mail: masashim@oita-u.ac.jp 
neurologic deterioration during surgery. Any distraction applied to the spinal column will close the lamina fracture and crush the entrapped neural elements [4]. The immediate postoperative neurologic loss and limited neurologic recovery are secondary to the crushing of the extruded neural elements in the vertical lamina fractures.

However, dural tears and cauda equina entrapment are very difficult to diagnose clinically or radiographically before surgery $[5,6]$. To date, dural tears have been traditionally diagnosed using conventional myelography, which cannot be performed unless the patient can tolerate the procedure without altering his/her neurologic status during the examination [7]. With advances in imaging technology, the evaluation of most spinal lesions is performed using high-resolution magnetic resonance imaging (MRI). MRI can directly depict spinal fractures, paraspinal and vertebral soft-tissue edema and ligamentous injuries $[8,9]$. However, there are no reports regarding the use of MRI for evaluating cauda equina entrapment in lamina fracture occurred with spinal burst fractures. The purpose of this study was to investigate predictable imaging findings suggestive of cauda equina entrapment in thoracolumbar and lumbar burst fractures.

\section{Materials and Methods}

\section{Patients}

From July 2005 to May 2010, we performed surgery on twenty-three patients at our institute in patients with thoracolumbar and lumbar burst fractures. Indications for surgery included neurological impairment and/or instability; and surgery was performed in patients with greater vertebral body compression and/or kyphosis. Patients with multi-level fractures, dislocation fracture or combined disk herniation were excluded. A review of all hospital clinical records and radiographs for these patients was conducted. Twenty-three patients (16 men and 17 women) were enrolled in the study. The average patient age at operation was 41.5 years (range, 16-76 years). Spinal burst fractures occurred between the T12 and L5 vertebrae. The neurologic status was determined according to Frankel classification at the time of injury. Frankel classification is graded as follows. Grade A: Complete neurological injury-no motor or sensory function clinically detected below the level of the injury. Grade B: Preserved sensation only-no motor function clinically detected below the level of the injury; sensory function remains below the level of the injury, but may include only partial function (sacral sparing qualifies as preserved sensation). Grade C: Preserved motor nonfunctional-some motor function observed below the level of the injury, but is of no practical use to the patient. Grade D: Preserved motor function-useful motor function below the level of the injury; patient can move lower limbs and walk with or without aid, but does not have a normal gait or strength in all motor groups. Grade E: Normal motor-no clinically detected abnormality in motor or sensory function with normal sphincter function; abnormal reflexes and subjective sensory abnormalities may be present. Each patient underwent anteroposterior and lateral view radiography, computed tomography (CT) and MRI. The patients were examined by open-book laminoplasty technique with a posterior approach (one patient with cauda equina entrapment had not undergone the open-book laminoplasty); and cauda equina entrapment were evaluated intraoperatively. Next, if any dural tear or cauda equina entrapment was found, it was repaired. All of twenty-three patients underwent posterior stabilization of their spine using transpedicular screw rod systems. The patients were classified into the entrapment and non-entrapment groups based on the presence or absence of cauda equina entrapment, which was surgically confirmed. Entrapment group consisted of six patients, all of whom had laminar fractures with dural tears. Nonentrapment group consisted of seventeen patients; and twelve of the patients had laminar fractures without dural tears. We investigated preoperative neurological status and the site of the laminar fracture and analyzed the spinal images with cauda equina entrapment.

\section{Analysis of the spinal images}

MRI of the spine was performed using a $1.5 \mathrm{~T}$ system and a spinal surface or phased-array coil. T1- and T2-weighted images of the sagittal and transverse planes were obtained. In T2-weighted images of the transverse plane, we defined cauda equina notch sign (CENS) as a v-shaped image that showed a lot of dots gathers between fractured lamina. We considered this sign to be indicative that entrapped cauda equina gathered between lamina fractures (Fig. 1). Lamina fractures were diagnosed using CT (Fig. 2). Fractured vertebrae were evaluated using CENS and the rate of available space for the spinal canal, at the nar- 
rowest portion of the burst fracture level (Fig. 3). The rate of available space was measured using the area of the normal spinal canal (B) and the remaining survival space of the spinal canal (A), drawn by an imaginary line at the narrowest burst fracture level. Percentage was calculated as follows: $\mathrm{A} / \mathrm{B} \times 100$. Intra- and interobserver reliability of the measured rate of available space in the spinal canal was estimated using intraclass correlation coefficients (ICC). We classified patients into two groups: entrapment

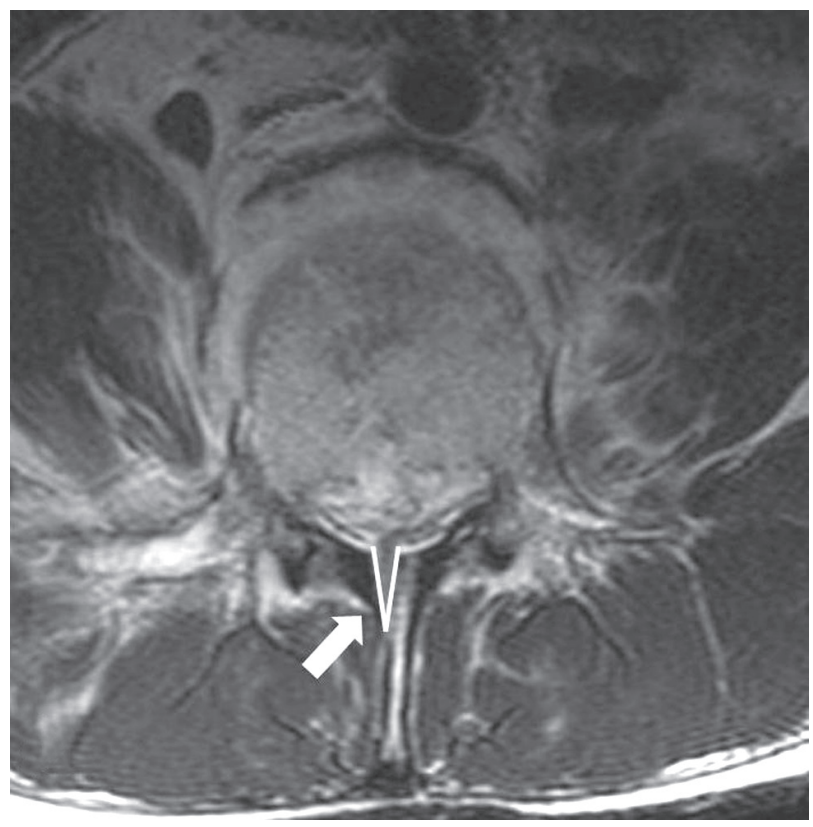

Fig. 1. Cauda equina notch sign was defined as a v-shaped image that entrapped cauda equina gathers (arrow) between lamina fractures.

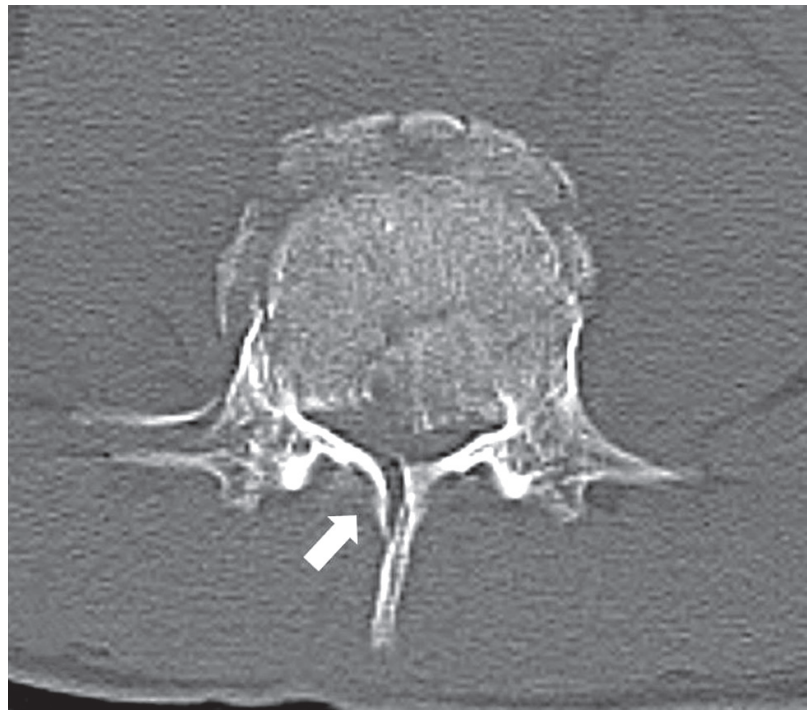

Fig. 2. Greenstick lamina fracture (arrow) associated with thoracolumbar and lumbar burst fractures. group and non-entrapment group, based on the presence or absence of cauda equina entrapment.

\section{Statistical analysis}

Fisher's exact probability test was used to determine the significance of association between cauda equina entrapment and CENS. Multivariate logistic regression analysis was used to estimate the association between Frankel classification and MRI findings, with the likelihood of cauda equina entrapment. All the statistical analyses were performed using SPSS statistical software (IBM Co., Armonk, NY, USA). Statistical significance was defined as $p<0.05$. Intra and interobserver reliability of measured rate of available space in the spinal canal were estimated using ICC by two independent observers. The agreement was rated as follows: poor, $r=0.0$ to 0.20 ; slight, $r=0.21$ to 0.40 ; fair, $r=0.41$ to 0.60 ; moderate, $r=0.61$ to 0.80 ; and substantial, $r>0.81$. A value of 1 indicated almost perfect, whereas a value of 0 indicated agreement no better than by chance.

\section{Results}

Demographic data on the patients included fracture level,

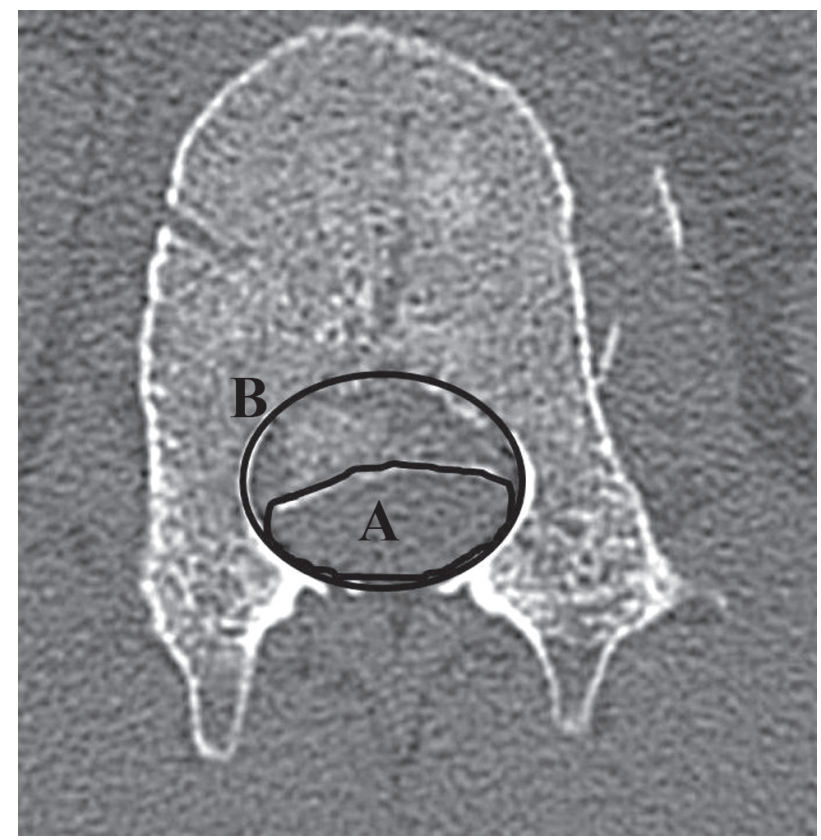

Fig. 3. The rate of available space in the spinal canal. The available space was measured using the area of the normal spinal canal $B$ and the remaining survival space of the spinal canal $A$, drawn by an imaginary area at the narrowest burst fracture level on the transverse image. Percentage was calculated using the formula $A / B \times 100$. 
Table 1. Data on the patients with burst fractures

\begin{tabular}{|c|c|c|c|c|c|c|}
\hline Case no. & Gender & Age (yr) & Level of injury & $\begin{array}{c}\text { Neurologic status } \\
\text { (Frankel classification) }\end{array}$ & $\begin{array}{l}\text { Lamina } \\
\text { fracture }\end{array}$ & CENS \\
\hline \multicolumn{7}{|c|}{ Entrapment group } \\
\hline 1 & Male & 20 & L4 & C & + & + \\
\hline 2 & Male & 76 & L3 & $\mathrm{D}$ & + & + \\
\hline 3 & Male & 56 & L4 & C & + & + \\
\hline 4 & Male & 38 & Ł4 & $D$ & + & + \\
\hline 5 & Male & 68 & L1 & D & + & + \\
\hline 6 & Male & 36 & L2 & C & + & + \\
\hline \multicolumn{7}{|c|}{ Non-entrapment group } \\
\hline 1 & Male & 48 & $\mathrm{~T} 12$ & E & - & - \\
\hline 2 & Female & 16 & $\mathrm{~L} 2$ & C & - & - \\
\hline 3 & Female & 27 & L3 & E & + & - \\
\hline 4 & Male & 40 & L2 & $\mathrm{E}$ & + & - \\
\hline 5 & Female & 25 & L1 & $E$ & + & - \\
\hline 6 & Male & 31 & L1 & E & + & - \\
\hline 7 & Female & 18 & L1 & $E$ & + & - \\
\hline 8 & Male & 33 & L1 & $C$ & - & - \\
\hline 9 & Female & 64 & L2 & $E$ & - & - \\
\hline 10 & Male & 19 & L1 & $C$ & + & - \\
\hline 11 & Female & 32 & L1 & E & + & - \\
\hline 12 & Male & 58 & L3 & $\mathrm{E}$ & + & - \\
\hline 13 & Male & 71 & L2 & $E$ & + & - \\
\hline 14 & Male & 45 & L2 & $\mathrm{E}$ & + & - \\
\hline 15 & Female & 19 & L5 & $C$ & + & - \\
\hline 16 & Male & 70 & L1 & E & + & - \\
\hline 17 & Male & 44 & L1 & C & - & - \\
\hline
\end{tabular}

According to the classification of Frankel (initial examination at follow-up). CENS, cauda equina notch sign; +, occurred; -, not occurred.

results of Frankel classification, MRI findings and lamina fractures (Table 1). In the entrapment group, \#3, \#1, \#1, and \#1 patient(s) had burst fractures at the L4, L3, L2, and L1 levels, respectively. In the non-entrapment group, $\# 8$, \#5, \#2, \#,1 and \#1 patient(s) had burst fractures at the L1, L2, L3, L5, and T12 levels, respectively. Lamina fractures were detected in 18 (78.3\%) and CENS was detected in $6(26.1 \%)$ of the 23 burst-fracture patients. All patients $(100 \%, 6 / 6)$ in entrapment group had a neurological deficit prior to surgical treatment; whereas, in non-entrapment group, the percentage of patients with a neurological deficit was $29.4 \%$ (5/17) before surgery. A preoperative neurological deficit in the presence of a burst fracture and an associated laminar fracture was a statisti- cally significant predictable risk factor of cauda equine entrapment $(p<0.05)$. CENS was detected in all patients in the entrapment group. On the other hand, CENS was not detected in any patients in the non-entrapment group (100\% in both sensitivity and specificity of CENS). Therefore, CENS was significantly associated with the presence of cauda equina entrapment.

According to logistic regression analysis, the rate of available space in the spinal canal was the most reliable of all the factors for suggesting the presence of cauda equina entrapment (odds ratio [OR], $0.83 ; p=0.025$ ) (Table 2). Patients were more likely to develop cauda equina entrapment if they had a burst fracture with a larger retropulsed fragment in the spinal canal. Statistical significance was 
Table 2. Logistic regression analysis for cauda equina entrapment

\begin{tabular}{lcc} 
Independent variable & OR (95\% CI) & $p$-value \\
Available space in the spinal canal (1\% increment) & $0.83(0.70-0.98)$ & 0.025 \\
Lamina fracture & $4.31(0.000)$ & 0.999 \\
Frankel classification & $2.26(0.37-13.80)$ & 0.376 \\
\hline
\end{tabular}

$\mathrm{OR}$, odds ratio; $\mathrm{Cl}$, confidence interval.

not observed for Frankel classification or lamina fracture $(p>0.05)$. We obtained excellent intra- and interobserver agreement with respect to the rate of available space in the spinal canal $(r=0.95)$.

\section{Discussion}

Burst fracture is defined as the failure of at least the anterior and middle columns of a vertebral segment due to axial compression, usually with some flexion [1]. Often, there is a retropulsion of one or more bony fragments into the neural canal with or without fractures in the lamina. Lamina fractures may be of complete or greenstick type and can be accompanied by a dural tear and cauda equina entrapment [4]. Dural tears and cauda equina entrapment may occur following burst fractures associated with separation of the pedicles; and neural elements are often entrapped between the fracture fragments of the lamina. In addition, dural tears increase the risk of meningitis, which in itself can act as a chronic focus for nerve root entrapment $[7,10]$. Denis and Burkus [4] noted a vertical lamina fracture that had occurred secondary to the splaying of the posterior arch of the vertebra under axial loading and described it as a greenstick fracture of the anterior cortex of the lamina. In our study, lamina fractures were detected in 18 (78.3\%) of the 23 burst fracture patients. It is important to investigate the presence of lamina fractures in burst fractures, because dural tear and cauda equina entrapment may occur. According to a study by Aydinli et al. [11], a 20\% increase in the interpedicular distance is associated with a $79 \%$ probability of developing a greenstick lamina fracture(s). Many investigators have found that a burst fracture with an associated lamina fracture is $100 \%$-sensitive and $74 \%$-specific for the presence of a dural tear $[3,12]$.

Cammisa et al. [12] and Miller et al. [3] observed that $36 \%$ and $44 \%$, respectively, of patients with a dural tear did have cauda equina entrapment. In addition, Cammisa et al. [12] observed a neurologic deficit in all patients with dural tears. The neurologic status of patients with burst fractures and greenstick lamina fractures depends on the degree of nerve root compression as well as the type of nerve roots that are entrapped [11]. There is a significant association between posterior element fracture and dural tear and between dural tear and severe neurologic deficit [13]. However, Ozturk et al. [14] reported that one patient with a greenstick lamina fracture was neurologically intact before surgery; however, the operation showed a dural tear and cauda equina entrapment. In our series, a patient with an L4 burst fracture and a greenstick lamina fracture developed immediate postoperative neurologic deterioration in the regions where the greenstick lamina fracture was ignored, despite using the posterior approach. Denis and Burkus [4] described a similar case that was attributed to the anterior approach being performed first, which possibly entrapped the cauda equine. Lumbar burst fractures with greenstick lamina fractures occur mostly in the L2-L4 area. During surgical treatment, any reduction maneuver will close the greenstick lamina fracture and crush the entrapped neural elements $[11,14]$. Therefore, it may be better to explore the greenstick lamina fracture, irrespective of any neural entrapment, before any reduction maneuver is performed.

However, it is not always possible to predict by preoperative investigation whether a patient without neurologic deficit, but with a greenstick lamina fracture, has a dural tear and/or cauda equina entrapment $[5,6,15]$. Although identification of dural tears or entrapped cauda equina before surgery is important, direct visualization of dural tears is often difficult. Dural tears traditionally have been diagnosed by conventional myelography; however, myelography does not provide significant information and can be harmful because of the positioning of the patient $[15,16]$. Unfortunately, many previous studies have not provided clearly suggestive radiographic findings of dural tears and cauda equina entrapment $[3,6,12]$. Aydinli et al. [11] described that posterior fat pad signals in CT and MRI disappeared in the presence of a greenstick 
lamina fracture and cauda equina entrapment. MRI gives excellent resolution for soft-tissue structures and fluids and, as such, is very sensitive for cerebrospinal fluid accumulation and pseudomeningoceles [17]. Recently, these injuries have been well-demonstrated using MRI techniques. MR myelography (MRM) with a very heavily T2-weighted sequence can produce an effect similar to that of conventional myelography $[18,19]$. However, MRM is not generally used at some institutions and is not included in routine spinal trauma protocols at some hospitals. Lee et al. [20] reported that dural tears were likely if MRI findings indicated lamina fracture, interpedicular distance $>28 \mathrm{~mm}$, central canal ratio $<0.46$ and an acute angle of the retropulsed fragment $<135^{\circ}$.

Our definition of CENS has not been reported in any previous study. In our series, CENS was detected in $26 \%$ of burst fracture patients. All the patients with CENS had cauda equina entrapment. Furthermore, although the size of the retropulsed fragment is significantly related to the risk of cauda equina entrapment $(\mathrm{OR}, 0.83)$ in our results, previous studies have shown that the degree of spinal canal narrowing is not correlated with the presence of a dural tear $[6,13]$. These imaging findings are useful to predict dural tears and cauda equina entrapment before surgery. It is important to explore and repair dural tears and cauda equina entrapment before any anterior or posterior spinal reduction maneuver, if CENS or a large retropulsed bony fragment is detected in thoracolumbar and lumbar burst fractures with greenstick lamina fractures.

Our study has several limitations. First, the number of patients included was too small. We should investigate more patients to clarify predictable imaging findings of cauda equina entrapment. Second, the exact measurement of the occupation rate of the retropulsed fragment was difficult, especially in cases of markedly unstable fractures. However, we did obtain excellent interobserver variability (ICC; $r=0.95)$.

\section{Conclusions}

Any distraction applied to the spinal column will close the greenstick lamina fracture and crush any entrapped neural elements. Thus, it is important to detect the presence of dural tears and cauda equina entrapment before surgery. CENS was the most predictable sign of cauda equina entrapment associated with burst fractures and greenstick lamina fractures. Furthermore, it is should be noted that larger the size of the retropulsed bony fragment, higher is the risk of developing cauda equina entrapment.

\section{Conflict of Interest}

No potential conflict of interest relevant to this article was reported.

\section{References}

1. Denis F. The three column spine and its significance in the classification of acute thoracolumbar spinal injuries. Spine (Phila Pa 1976) 1983;8:817-31.

2. Keenen TL, Antony J, Benson DR. Dural tears associated with lumbar burst fractures. J Orthop Trauma 1990;4:243-5.

3. Miller CA, Dewey RC, Hunt WE. Impaction fracture of the lumbar vertebrae with dural tear. J Neurosurg 1980;53:765-71.

4. Denis F, Burkus JK. Diagnosis and treatment of cauda equina entrapment in the vertical lamina fracture of lumbar burst fractures. Spine (Phila Pa 1976) 1991;16(8 Suppl):S433-9.

5. Pau A, Silvestro C, Carta F. Can lacerations of the thoraco-lumbar dura be predicted on the basis of radiological patterns of the spinal fractures? Acta Neurochir (Wien) 1994;129:186-7.

6. Silvestro C, Francaviglia N, Bragazzi R, Piatelli G, Viale GL. On the predictive value of radiological signs for the presence of dural lacerations related to fractures of the lower thoracic or lumbar spine. J Spinal Disord 1991;4:49-53.

7. Morris RE, Hasso AN, Thompson JR, Hinshaw DB Jr, Vu LH. Traumatic dural tears: CT diagnosis using metrizamide. Radiology 1984;152:443-6.

8. Lee RR. MR imaging and cervical spine injury. Radiology 1996;201:617-8.

9. Flanders AE, Schaefer DM, Doan HT, Mishkin MM, Gonzalez CF, Northrup BE. Acute cervical spine trauma: correlation of MR imaging findings with degree of neurologic deficit. Radiology 1990;177:25-33.

10. Eismont FJ, Wiesel SW, Rothman RH. Treatment of dural tears associated with spinal surgery. J Bone Joint Surg Am 1981;63:1132-6.

11. Aydinli U, Karaeminogullari O, Tiskaya K, Ozturk C. Dural tears in lumbar burst fractures with greenstick 
lamina fractures. Spine (Phila Pa 1976) 2001;26:E4105.

12. Cammisa FP Jr, Eismont FJ, Green BA. Dural laceration occurring with burst fractures and associated laminar fractures. J Bone Joint Surg Am 1989;71:1044-52.

13. Pickett J, Blumenkopf B. Dural lacerations and thoracolumbar fractures. J Spinal Disord 1989;2:99-103.

14. Ozturk C, Ersozlu S, Aydinli U. Importance of greenstick lamina fractures in low lumbar burst fractures. Int Orthop 2006;30:295-8.

15. McAfee PC, Yuan HA, Fredrickson BE, Lubicky JP. The value of computed tomography in thoracolumbar fractures. An analysis of one hundred consecutive cases and a new classification. J Bone Joint Surg Am 1983;65:461-73.
16. Brant-Zawadzki M, Jeffrey RB Jr, Minagi H, Pitts LH. High resolution CT of thoracolumbar fractures. AJR Am J Roentgenol 1982;138:699-704.

17. Bosacco SJ, Gardner MJ, Guille JT. Evaluation and treatment of dural tears in lumbar spine surgery: a review. Clin Orthop Relat Res 2001;(389):238-47.

18. Ross JS, Modic MT. Current assessment of spinal degenerative disease with magnetic resonance imaging. Clin Orthop Relat Res 1992;(279):68-81.

19. Jensen MC, Kelly AP, Brant-Zawadzki MN. MRI of degenerative disease of the lumbar spine. Magn Reson Q 1994;10:173-90.

20. Lee IS, Kim HJ, Lee JS, et al. Dural tears in spinal burst fractures: predictable MR imaging findings. AJNR Am J Neuroradiol 2009;30:142-6. 